\title{
Mapping Qtls for Grain Yield and Yield Components in Kenyan Maize (Zea mays L.) Under Low Phosphorus Using Single Nucleotide Polymorphism (SNPS)
}

\author{
Evans Ochieng Ouma, Gudu Samuel \\ Rongo University, Rongo, Kenya \\ Email: evans.ouma1@gmail.com
}

How to cite this paper: Ouma, E.O. and Samuel, G. (2021) Mapping Qtls for Grain Yield and Yield Components in Kenyan Maize (Zea mays L.) Under Low Phosphorus Using Single Nucleotide Polymorphism (SNPS). American Journal of Plant Sciences, 12, 1106-1123.

https://doi.org/10.4236/ajps.2021.127077

Received: June 3, 2021

Accepted: July 25, 2021

Published: July 28, 2021

Copyright $\odot 2021$ by author(s) and Scientific Research Publishing Inc. This work is licensed under the Creative Commons Attribution International License (CC BY 4.0).

http://creativecommons.org/licenses/by/4.0/

\begin{abstract}
Selection for tolerance to low phosphorus $(\mathrm{P})$ using morphological traits alone is slow and often confounded by environmental effects. This study identified some Quantitative Trait Loci (QTLs) associated with grain yield (GYLD), Plant (PHT) and Ear heights (EHT) under low $\mathrm{P}$ in maize using single nucleotide polymorphic markers. 228 F2:3 individuals derived from a cross between two contrasting maize inbred lines together with 239 SNPs were mapped onto ten linkage groups (LGs) spanning 2255 centiMorgans (cM) with an average inter-marker distance of $9.44 \mathrm{cM}$. Majority of the SNP markers (63\%) followed the Mendelian segregation and were fairly distributed in all the LGs. Mean performance for all the traits in the F3 population was higher than the parental values, which suggested transgressive segregation for all traits. Low to moderate broad sense heritability $(0.35-0.50)$ in the F3 population for GYLD, PHT and EHT indicated that tolerance to low $\mathrm{P}$ is controlled by complex multi genetic factors. A full multi-QTL model analysis suggested six QTLs (2 QTLs each for GYLD, PHT and EHT) located on chromosomes 1, 3, 4 and 8. The two QTLs for GYLD increased maize yield under low P soils by $173 \mathrm{~kg} / \mathrm{ha}$ while the 2 QTLs for PHT increased plant growth by $18.14 \mathrm{~cm}$. The \% phenotypic variance explained by these QTLs under low $\mathrm{P}$ environments had a wide range $(0.242 \%-53.34 \%)$ and was much lower for GYLD compared to plant growth. Both additive and dominance gene actions contributed differentially to the observed phenotypic variance for tolerance to low $\mathrm{P}$ soils with dominance contributing more genetic effects compared additive effects for majority of the QTLs. The findings of this study will provide some basis for marker-assisted selection for yield improvement and further guide breeding strategies under low $\mathrm{P}$ soils of west-
\end{abstract}


ern Kenya.

\section{Keywords}

SNP Markers, Additive, Dominance, Heritability, Low P, Maize, QTLs

\section{Introduction}

Phosphorus $(\mathrm{P})$ is one of the most important plant nutrients, contributing approximately $0.2 \%$ of a plant's dry weight, and is a component of key organic molecules such as nucleic acids, phospholipids and energy transfers [1]. However, in the tropics, it is mainly unavailable to plants due to formation of poorly soluble $\mathrm{P}$ complexes with calcium in alkaline and aluminium and iron in acidic soils thereby causing an important constraint to crop production [2] [3]. Therefore sustainable agricultural production requires improved $\mathrm{P}$ management strategies [4]. Strong reliance on phosphorus (P) fertilization to maintain yields and quality of crops in low $\mathrm{P}$ soils is greatly challenging as $\mathrm{P}$ fertilizers are costly and derived from limited \& non-renewable sources (rock phosphate) [5] [6]. Therefore, breeding effort to develop P-efficient maize varieties is a valid and necessary approach as part of the long term P-deficiency management strategies for improving yield and enhancing food security in low P soils [7]. However breeding and selection using morphological trait/markers alone is slow and often confounded by genotype by environment interactions on some of the major P-efficiency selection parameters such as grain yield, Plant height, Ear height, cob length \& root traits which have complex inheritance and sometimes exhibit very low heritability under stressful environments [8] [9] [10]. The use of genetic markers and molecular tools alongside the conventional strategies is of necessity to speed up the breeding process and improve its accuracy and reliability. Several genetic markers have been used including restriction fragment length polymorphism (RFLP), amplified fragment length polymorphism (AFLP), simple sequence repeats (SSRs) and single nucleotide polymorphisms (SNPs) for map construction and to identify useful QTLs for yield improvement in maize with studies using SSRs dominating [11] [12] [13] [14]. However, they have several limitations including low level automation of their methods, difficulty in typing many loci in a single reaction, low abundance in the genome, and time-consuming analysis requiring large numbers of loci [15]. Therefore recent advances in molecular technology have preferred SNP markers [9] [16] [17] over (or in addition to) microsatellites and other markers in mapping studies. SNPs have high genomic abundance, good potential for high through put analysis and lower genotyping error rates, and can easily be typed on a much larger scale, low cost per data point, locus-specificity, and codominance [18] [19]. Therefore SNPs have emerged as a powerful tool for many genetic applications [9] [20]. Consequently this study adopted the use of SNPs for QTL analysis in maize using the Kompetitive Allele Specific PCR genotyping system (KASPar) developed by LGC 
Genomics [21].

At present phosphorus uptake 1 ( Pup 1) gene is one of the P-related QTL that has been identified in rice variety kasalath. Pup 1 breeding lines have proven effective in field trials under low P soils [22] [23] [24]. These authors further showed that overexpression of the threonine receptor-like kinase, phosphorus starvation tolerance1 (OSPSTOL1) significantly increased grain yield in rice cultivated under phosphorus deficient soils via OSPSTOL1-elicited enhancement of early root growth and development thereby enabling plants to acquire more phosphorus and other nutrients. [25] investigated the role of homologs of PSTOL1 in sorghum (SbPSTOL1) under low P soils and reported that SbPSTOL1 genes localized with QTLs for traits underlying root morphology and dry weight accumulation under low P. The SBPSTOL1 alleles reduced root diameter which was associated with enhanced P uptake under low P while both Sb03g006765 and Sb03g0031680 alleles increased root surface area resulting into increased grain yield in low-P soils. These authors therefore suggested that PSTOL1 gene enhanced $\mathrm{P}$ acquisition and performance of sorghum under low $\mathrm{P}$ soils. Further studies in sorghum have reported pleiotropic QTLs for fine roots, root diameter and grain yield which were all near sorghum homologs of the rice serine/ threonine kinase, OsPSTOL1 [26]. They concluded that another PSTOL1-like gene, Sb07g02840, appears to enhance grain yield via small increases in root diameter. However, majority of the QTL studies in maize have attempted to detect QTLs for phosphorus efficiency traits only at initial stages of plant development either based on shoot dry weight [27] [28] [29] or using root morphology characteristics [30] [31] as this is often faster and less risky in terms of field experimental failures that are commonly experienced when screening genotypes under very low $\mathrm{P}$ soils. Only a few studies have attempted to use grain yield under low P soils for QTL studies [32]. Studies by [31] using maize seedlings reported putative homologs to PSTOL1, where 13 genomic regions were significantly associated with total dry weight and $\mathrm{P}$ content in maize seedling under low-P availability in a complementary way. Other available studies in maize such as [14] reported QTLs associated with yield traits such as 100-kernel weight, ear length, ear diameter, ear weight, and grain weight per plant but were not necessarily targeting tolerance to low $\mathrm{P}$ as they were not done under $\mathrm{P}$ deficient soil conditions. Therefore, more information is still needed in maize grown under low $\mathrm{P}$ conditions in order to guide breeding strategies for the development of maize cultivars more adapted to low $\mathrm{P}$ conditions in tropical soils. This study intended to identify single nucleotide polymorphic markers (SNPs) that are linked to the major QTL(s) associated with grain yield, Plant and Ear heights using 228 F2:3 individuals derived from a cross between maize inbred lines contrasting in tolerance to low $\mathrm{P}$.

\section{Materials and Methods}

\subsection{Genetic Material}

A total of two hundred and twenty eight F2 plants derived from KML 036 X S 
396-16-1 maize inbred lines contrasting for P-efficiency were used in this study. The inbred line KML 036 is P-efficient while S 396-16-1 is P-inefficient [10]. Both lines are white seeded. The 2 inbred lines were crossed to generate F1 progenies which were advanced to F2 through selfing Two hundred and twenty eight F2:3 were raised and phenotyped under very low $\mathrm{P}$ conditions in migori site.

\subsection{Leaf Sampling, Genomic DNA Extraction and Quantification}

Maize leaf samples were obtained from 3 weeks old maize seedlings using LGC genomics leaf sampling Kit contained 96-well storage plate from the field. Sample leaves were placed on the Harris cutting mat and leaf disks were cut in rolling circular motion using $6 \mathrm{~mm}$ clean Harris Uni-Core cutting tool. The plunger on the cutting tool was then depressed swiftly to release the leaf disc into the appropriate wells. The cutting end of Harris Uni-core cutting tool was rinsed several times in $2 \% \mathrm{NaClO}$ (sodium hypochlorite) washed 5 times in water and dried on paper towel before using it in the next leaf sample

(http://www.finnzymes.com/directpcr/harris_unicore.html). The above procedure was repeated until all the parental and the F2 samples were completed. The plates were then sealed with a perforated (gas permeable) heat seal, packaged in a heavy duty and sealed in the presence of a desiccant (Silica gel) to dehydrate and hence preserve the leaf tissue during transit from field at ambient temperature. Genomic DNA was extracted from dried young leaf samples using kleargene leaf DNA extraction Miniprep Kit [21] [33]. DNA pellets were kept at room temperature for 30 minutes and then dissolved into $200 \mathrm{uL}$ of $0.1 \times T E$ buffer. DNA was quantified using Quant-iTTM PicoGreen dsDNA Assay Kit (Invitrogen San Diego, CA) and the fluorescence measured using the Microtiter plate reader (Varioscan from Thermo Scientific). Samples were adjusted to $40 \mathrm{ng} / \mu \mathrm{l}$ using Tris-EDTA buffer [34].

\subsection{Selection of Polymorphic SNP Markers}

The DNA from the two parental lines (KML 036 and S 396-16-1) were genotyped for polymorphism using a total of 1250 random SNP chip developed at Cornell University, out which the 466 polymorphic SNPs were selected based on the Nucleotide SNP calling of the parental samples [35]. The F2 DNA samples were then assayed using 466 polymorphic SNPs at LGC genomics laboratory in the UK.

\subsection{SNP Genotyping and PCR Amplification}

SNP genotyping was carried out using Kompetitive Allele Specific PCR (KASP) using the LGC genomics KASP system [36]. KASP assay components used for SNP genotyping comprised: primer mix and KASP PCR master mix. The primer mix contained $0.05-0.07 \mu \mathrm{M}$ of each of the 2 unlabelled allele specific forward primers and $0.07-0.20 \mu \mathrm{M}$ of one common unlabelled reverse primer. The 
KASP PCR master mix contained 0.2 - $0.5 \mathrm{uM}$ of klear Taq polymerase, 0.05 $0.20 \mathrm{Mm}$ of each dNTPs, 1 - $2 \mu \mathrm{l}$ of $1 \mathrm{x}$ PCR Buffer (10 mM Tris- $\mathrm{HCl}, \mathrm{Ph} 8.3$ ), 1.8 - $2.8 \mathrm{mM} \mathrm{MgCl}_{2}$ and two distinct FRET (fluorescence resonant energy transfer) cassettes; one labelled with FAM $^{\mathrm{m}}$ dye (Emission wave length 485 - $520 \mathrm{~nm}$ ) and the other with $\mathrm{HEX}^{\mathrm{TM}}$ dye (Emission wave length 535-M556 nm) in the corresponding quencher. The passive reference dye succinimidyl ester (ROX) (Emission wave length $575-610 \mathrm{~nm}$ ) was used to allow normalisation of variations in signal caused by differences in well to well liquid volume. The KASP homogenous assay was added to each of the $2-2.5 \mu \mathrm{l}(1-10 \mathrm{ng} / \mu \mathrm{l})$ DNA samples with total reaction optimized to $4-10 \mu \mathrm{l}$ volume in each of the 384 well PCR plates (http://www.lgcgenomics.com/kasp-genotyping-reagents). Two no template controls (NTCs) were included on each genotyping plate. The volumes of the reagents and reaction volumes were calculated using a standard procedure given by the manufacturer in a spread sheet found at

http://www.kbioscience.co.uk/download/index.html. The PCR plates were then sealed with a clear seal using Fusion Laser welding system and placed into the Hydrocycler water bath-based thermocycler where the PCR reaction was initiated. The thermocycler regimes were set at initial denaturation at $94^{\circ} \mathrm{C}$ for 15 minutes followed by 10 cycles of $20 \mathrm{~s}$ at $94^{\circ} \mathrm{C}$, annealing for $60 \mathrm{~s}$ at touch down temperatures declining from $65^{\circ} \mathrm{C}-57^{\circ} \mathrm{C}$ (dropping by $0.8^{\circ} \mathrm{C}$ per cycle) and extension for $10 \mathrm{~s}$ at $72^{\circ} \mathrm{C}$. Then another 26 cycles for $20 \mathrm{~s}$ at $94^{\circ} \mathrm{C}, 60 \mathrm{~s}$ at $57^{\circ} \mathrm{C}$ and extension for $40 \mathrm{~s}$ at $72^{\circ} \mathrm{C}$

(http://www.lgcgenomics.com/genotyping/kasp-genotyping-reagents/).

\subsection{Plate Reading and Analysis of SNP Genotyping Data}

An in point reading of KASP PCR data was done using Real time PCR machine (RTPCR) (Applied Biosystems-http://www.appliedbiosystems.com) at between $20^{\circ} \mathrm{C}-40^{\circ} \mathrm{C}$ in order to capture both the $\mathrm{FAM}^{\mathrm{rm}}$ and the $\mathrm{HEX}^{\mathrm{sm}}$ dye signals

(http://www.kbioscience.co.uk//KASP_manual.pdf). The data was then imported into the Kluster Caller software

(http://www.kbioscience.co.uk/software/klustercaller) for automatic SNP calling for each locus. Data was automatically read by the software and checked manually for errors and rescored while designating homozygous and heterozygous clusters. Using this software, the FAM and HEX data were plotted on the $\mathrm{x}$ and $\mathrm{y}$ axes, respectively which automatically created a genotype cluster diagram for all genotypes at each SNP. Passive reference dye (ROX) was used to normalise the data by dividing FAM and HEX values by the passive reference value for the particular wells, thus removing the variable of liquid volume. Genotypic classes were then determined according to sample clusters using the FAM and the HEX fluorescence. The presence of the same fluorescence dye signal alone (FAM) (Red) indicated that the DNA sample was homozygous for one allele while the HEX (Blue) dye signal alone indicated that the DNA sample was homozygous for the other allele. A 50/50 mixture (Green) of the two dyes indicated heterozy- 
gous DNA samples. The Cluster data was viewed graphically using SNP Viewer version 3.2 .

\subsection{Construction of Genetic Linkage Map}

The map was generated based on 239 polymorphic SNPs and 228 F2 families. The results of the SNP alleles were converted to marker data by formatting using Microsoft excel and data analysed by ICiMapping software version 3.2 [37]. Goodness of fit test was performed using Chi-square test $(\mathrm{p}=0.05)$ for the conformity to the expected Mendelian segregation ratio of 1:2:1. Markers were ordered with the regression mapping algorithm and were classified into Linkage groups (LGs) using the grouping module at LOD thresholds of $7-8.0$ at an increment of 0.5 .

Linkage groups were determined at LOD 8.0 with a recombination frequency smaller than 0.49 and a maximum threshold value of $5 \mathrm{cM}$ for the jump. The best marker order was determined using the "Ripple" function (value of 1). Recombination frequencies between marker loci was estimated using the maximum likelihood estimate (MLE) of the recombination fraction and converted to map distances in centiMorgans (cM) using the Kosambi mapping function [38].

\subsection{Phenotyping of F2:3 Populations in Low P Soils}

Out of the 228 F2:3 progenies of the cross KML 036 X S 396-16-1 genotyped, only 208 were evaluated at Migori site in the long rain season of 2015. The rest did not have adequate seeds for evaluation. The experiment was laid out in a $16 \times 13$ resolvable alpha lattice incomplete block design replicated three times. Sixteen genotypes were blocked together in each of the 13 incomplete blocks. Randomization and field layout was generated by Genstat version 18 [39]. The plants were grown in single row plots of $3 \mathrm{~m}$ long using a spacing of $0.75 \times 0.30$ m. Six weeks after sowing, all the plots were top dressed using Calcium Ammonium nitrate (CAN) at $75 \mathrm{~kg} \mathrm{~N} / \mathrm{ha}$. Weeding was done manually thrice and the crop protected from stalk borer (Buseolafusca L.) damage using 2 - 3 granules of Beta-cyhalothrin (Bulldock GR 0.05) at a rate of $6 \mathrm{~kg} \cdot \mathrm{ha}^{-1}$ applied in the whorl of each plant after thinning. Data was scored for grain yield, plant height and ear height from a sample of 8 plants per plot drawn from inner rows.

\subsection{Statistical Analysis}

Field data was analysed by Linear mixed models (REML) using Genstat version 18 to obtain means and variance components under low $\mathrm{P}$ among the 208 genotypes. The genotypes were considered fixed while the blocks, as random effects when fitting the mixed model in order to determine the genotypic effects. The genotypic mean of the F2:3 families (BLUEs-best linear Unbiased estimates) were used for QTL analysis. The following model was fitted and used to analyse the data

$$
\underline{Y}_{-i j m}=\mu+\rho_{j}+\underline{B}_{m(j)}+G_{i}+\grave{\varepsilon}_{i j m}[40]
$$


where $\underline{Y}_{-i j m}$ is the observation on the $i j m^{\text {th }}$ plot.

$\mu$ is the general mean, $\rho_{j}$ is the effect due to the fixed $f^{\text {th }}$ replication, $\underline{B}_{m(j)}$ is the effect due to the $m^{\text {th }}$ random incomplete block nested within replicate.

$G_{i}$ is the effect due to the $I^{\text {th }}$ genotype in the $m^{\text {th }}$ block, of the jth replicate.

$\underline{\dot{\varepsilon}}_{i j m}$ is the residual effect due to $i j m^{\text {th }}$ plot.

\subsection{Estimation of Heritability}

Broad sense heritability $\left(H^{2}\right)$ was estimated by variance components using linear mixed models (REML) of Genstat version 18. Broad-sense heritability was calculated as follows:

$$
H^{2}=\sigma_{g}^{2} /\left\{\sigma_{g}^{2}+\left(\sigma_{\text {error }}^{2} / r\right)\right\}
$$

where $H^{2}$ is broad sense heritability, $\sigma_{g}^{2}$ is the generic variance; $\sigma_{\text {error }}^{2}$ is the error variance; $r$ is the number of replicates per genotype [41].

\subsection{QTL Analysis}

Phenotypic mean values of 208 F2:3 families and linkage map data were used to perform QTL analysis for plant height, ear height and grain yield. A composite interval mapping method (CIM) [42] [43] was used in GenStat software version 18 [39]. QTL detections were performed every $5 \mathrm{cM}$ along the chromosomes. In the first step, simple interval mapping was performed and cofactors selected [44]. For co-factor selection, F-to enter and F-to drop threshold was set at 6.0 to avoid selecting multiple markers linked to one QTL as co-factors [22]. Using these cofactors to reduce the residual variation, QTLs were detected using composite interval mapping (CIM) [43] where further runs were done with all markers on chromosomes selected as co-factors in order to detect multiple QTLs on chromosomes with greater resolutions [45]. QTL detections were performed every $5 \mathrm{cM}$ along the chromosomes and a final multi-QTL model was fitted based on [37]. Likelihood ratio statisticts based on permutations $(-\log 10(\mathrm{P}))$ with LOD score of $>3.0$ considered significant for QTL detection [46].

\section{Results and Discussion}

\subsection{Screening SNP Markers for Polymorphism}

A total of 1250 useful SNP markers from maize genome were used to genotype the two maize parental lines (KML 036, S 396-16-1) for polymorphism out of which 1165 (93.2\%) were reported. The remaining (85) were not included in the analysis due weak amplication, irreproducibility in allele calling or had more than $10 \%$ missing data. Out of the 1165 SNPs, 80 were mono-allelic and were also excluded from the subsequent analysis hence only 1085 markers were analysed for polymorphism in the two parental lines. In the 1085 SNPs, base changes involved A/C (182), A/G (708), A/T (68) and C/G (127) with the A/G changes accounting for the highest $(65.3 \%)$ and $\mathrm{A} / \mathrm{T}$ the lowest $(6.2 \%)$ of the informative SNPs (Figure 1). Results showed that only 466 SNP markers were polymorphic. 


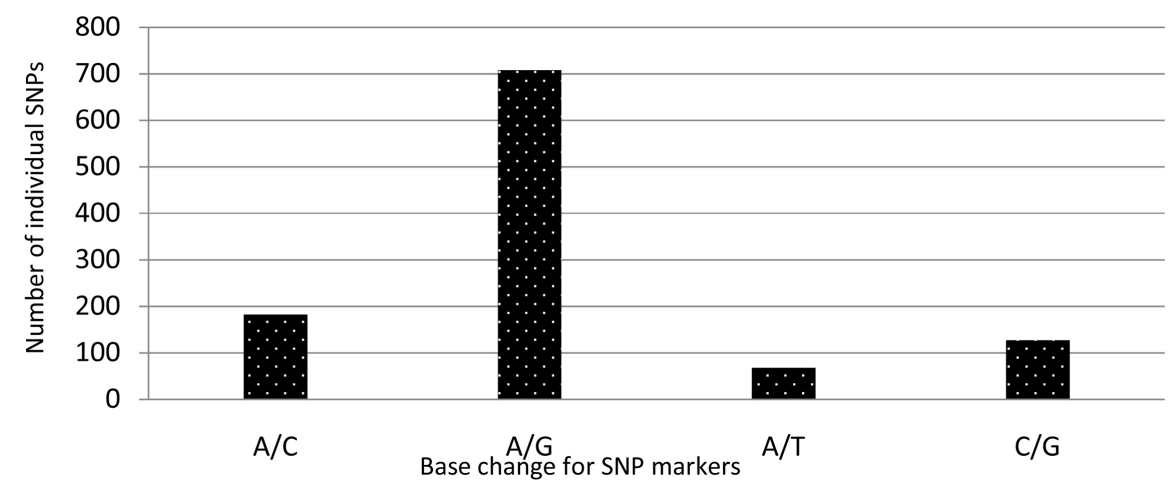

Figure 1. Frequency of allelic base change in polymorphic SNP used to genotype.

\subsection{SNP Genotyping of F2 Segregating Population}

Most of the SNP markers produced three main clusters representing the two homozygous (AA/GG \& CC/TT) and one heterozygous (AG/AC/AT) genotypes expected of F2 segregating population was used (Figure 2(a)). A total of 436 SNPs were successfully genotyped in the F2 segregating population giving a success rate of $93.2 \%$. The remaining 30 (6.8\%) SNP markers did not produce clearly well separated clustering patterns hence were considered as technically unsuccessful and were excluded from the analysis. Out of the 436 successful SNPs, 52 SNP markers were considered false (failed to detect a SNP in the F2 segregating population) that grouped into a single cluster (e.g. PHM1870_20 in Figure 2(c)). Another $125 \mathrm{SNPs}$ produced only two clusters representing the two homozygous groups (Figure 2(b)) while while 20 others had ambiguous data points located outside these clusters (indicated by arrows in Figure 2(d)) and represented missing data.

Therefore only 239 SNPs were considered informative in the maize F2 segregating population. These results compare well with those of [34] who genotyped 768 SNPs in Chick pea (Cicer arietinum L.) recombinant inbred lines (RILs) using Illumina Golden Gate assays (GGGT) and reported similar SNP clustering patterns. They also agree well with those of [35] who reported missing SNP data, ambiguity, irreproducibility in allele calling in $30.7 \%$ of the SNPS they used in diverse CIMMYT maize inbred lines. A sample view of the segregation of the maize F2:3 in chromosomes 2 and 8 as viewed using flapjack software [47] are shown in Figure 3.

\subsection{SNP Genetic Mapping}

Two hundred and thirty nine (239) markers were mapped onto the ten linkage groups spanning 2255 centiMorgans (cM) with an average inter-marker distance of $9.44 \mathrm{cM}$. The LGs were numbered (1 to 10 ) based on the common marker positions shared between corresponding LGs from previous studies [31] [35] [48]. The genetic length of the LGs ranged from $117.818 \mathrm{cM}$ (LG 6) to $425.52 \mathrm{cM}$ (LG2) (Table 1). The markers were unevenly and non-randomly distributed in the LGs with LG 8 being the most saturated (43 markers) with an average 


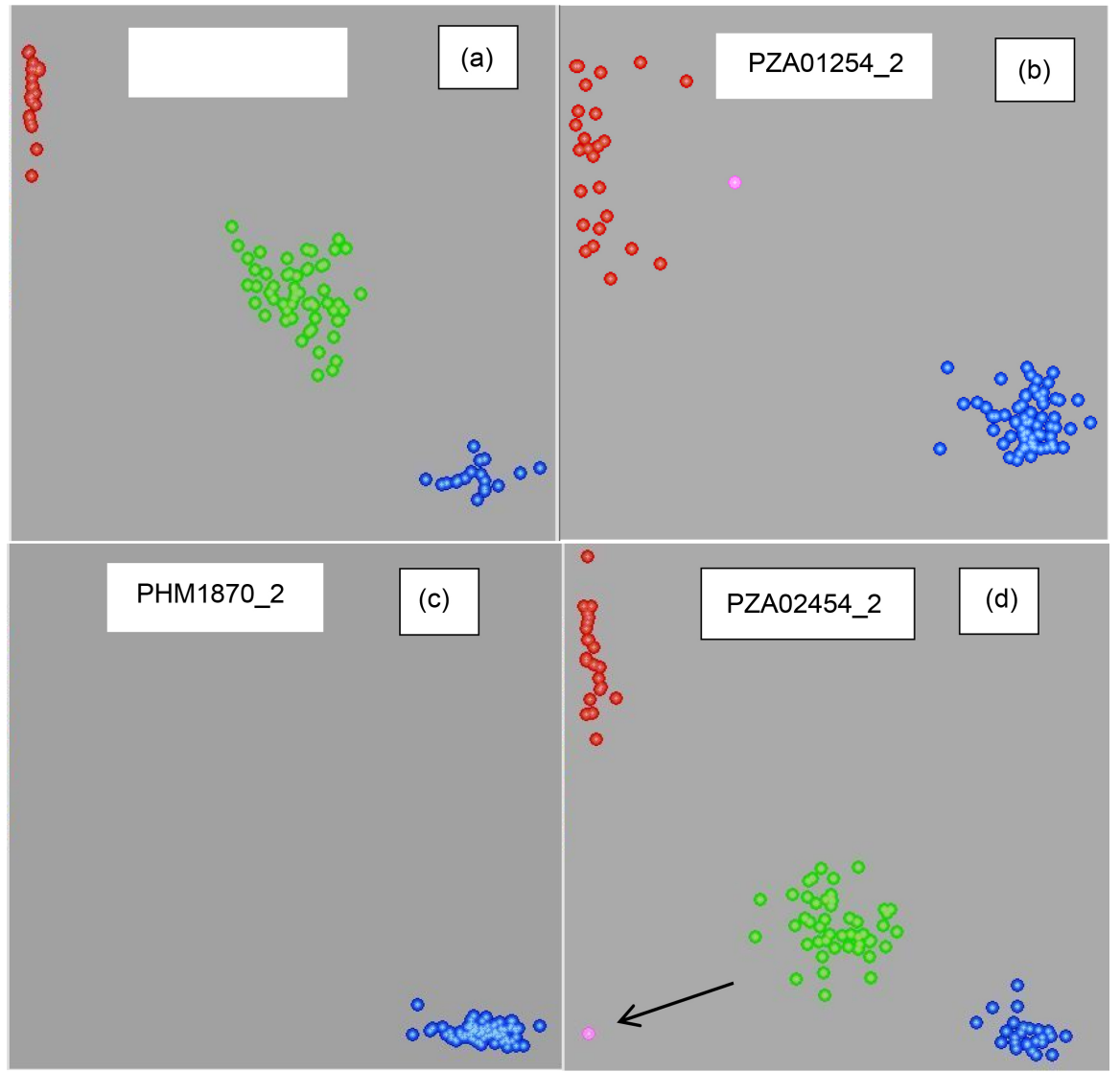

Figure 2. (a)-(d): Representative clustering patterns generated by the KASP SNP Genotyping assay for F2 segregating population. Red colour shows Calls that have been assigned to allele 1 (G:G/A:A/T:T). These are homozygous for one allele. Green colour shows Calls that have been assigned to allele $1 \& 2$. These are heterozygous for the two allele (G:A/A:T/G:C), Blue colour shows Calls that have been assigned to allele 2. These are homozygous for the other allele (A:A/T:T/C:C) and Pink colour shows Calls that were not scored because they were unreliable.

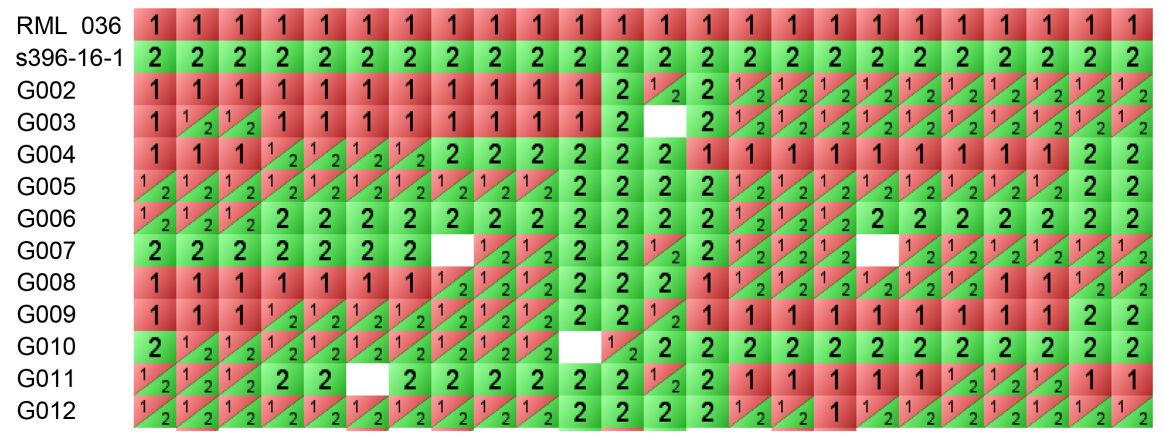

Figure 3. Flapjack image for Segregation of maize F2 genotypic data on chromosome 2. 1 represents homozygotes for parent 1 (AA/GG) while 2 homozygotes for parent 2 (CC/TT) while $1 / 2$, represents heterozygotes (AG/AC/AT).

marker density of $7.72 \mathrm{cM}$, whereas LG7 had the least number of markers (only 9) implying that some other potential QTLs could have been uncovered (Table 1). On an average, one linkage group contained 23.9 markers that spanned an 
Table 1. Distribution of SNP markers on the ten maize linkage groups.

\begin{tabular}{cccccc}
\hline $\begin{array}{c}\text { Linkage } \\
\text { group }\end{array}$ & Length & $\begin{array}{c}\text { Number } \\
\text { of }\end{array}$ & Average & Median distance & $\begin{array}{c}95 \% \\
\text { percentile }\end{array}$ \\
\hline 1 & Cm & markers & $\begin{array}{c}\text { Length } \\
(\mathrm{cM})\end{array}$ & between markers & $\begin{array}{c}\text { of distances } \\
(\mathrm{cM})\end{array}$ \\
\hline 2 & 154.3 & 20 & 7.72 & 1.8 & 50.5 \\
3 & 425.4 & 36 & 11.82 & 5.9 & 40.3 \\
4 & 138.9 & 27 & 5.14 & 0.5 & 41.1 \\
5 & 243.4 & 20 & 12.17 & 3.1 & 78.2 \\
6 & 118.1 & 22 & 5.37 & 0.7 & 30.4 \\
7 & 117.8 & 21 & 5.61 & 1.2 & 38.7 \\
8 & 413.9 & 9 & 45.99 & 4.1 & 136.6 \\
9 & 331.8 & 43 & 7.72 & 3.3 & 34.8 \\
10 & 145.4 & 26 & 5.59 & 3.2 & 19.1 \\
Genome & 166.4 & 15 & 11.09 & 1.7 & 72.9 \\
\hline
\end{tabular}

average of $94.4 \mathrm{cM}$. The median distance between markers ranged from $0.5-41$ $\mathrm{cM}$ with an average of $2.6 \mathrm{cM}$.

The $\mathrm{x}^{2}$ test performed showed segregation distortion (SDST) for $37 \%$ of the marker loci. However these markers were finally integrated into the map in order to minimize loss of genetic information related to these markers. Moreover, the distorted markers were found to be widely distributed throughout all the LGs even though the ratios varied from one LG to another. For example LG 6 showed the highest distortion (8.3\%) while LG 3 the least (2.1\%) (Figure 4). The overall segregation distortion of $37 \%$ observed in this study compared well with those of [34] [49] who reported SDST of $41.3 \%$ and $42 \%$ respectively in bean population.

\subsection{Phenotypic Analysis, Heritability and Correlations in Parental and F3 Population}

Means and broad-sense heritability for GYLD, PHT and EHT are presented in Table 2. Mean performances observed in all the traits in F3 population was higher than the parental values, which suggested transgressive segregation with respect to parental values for all traits. This finding may also suggest the absence of epistasis for the inheritance of these traits under low P soils (Table 2). This study compares well with those of [50] who reported transgressive segregation for maize hybrids under low P soils. Broad sense heritability ranged from 0.35 0.50 among the phenotypic traits studied and was highest PHT and lowest in GYLD. The low to moderate heritability values based on family means for the various traits (GYLD, PHT and EHT) indicate that tolerance to low P and the measured traits are complex multi genetic factors each regarded as quantitative trait loci (QTL) as have been suggested by [9] [22]. The low to moderate heritability under stress conditions has also been reported by [51] [52] and was generally 


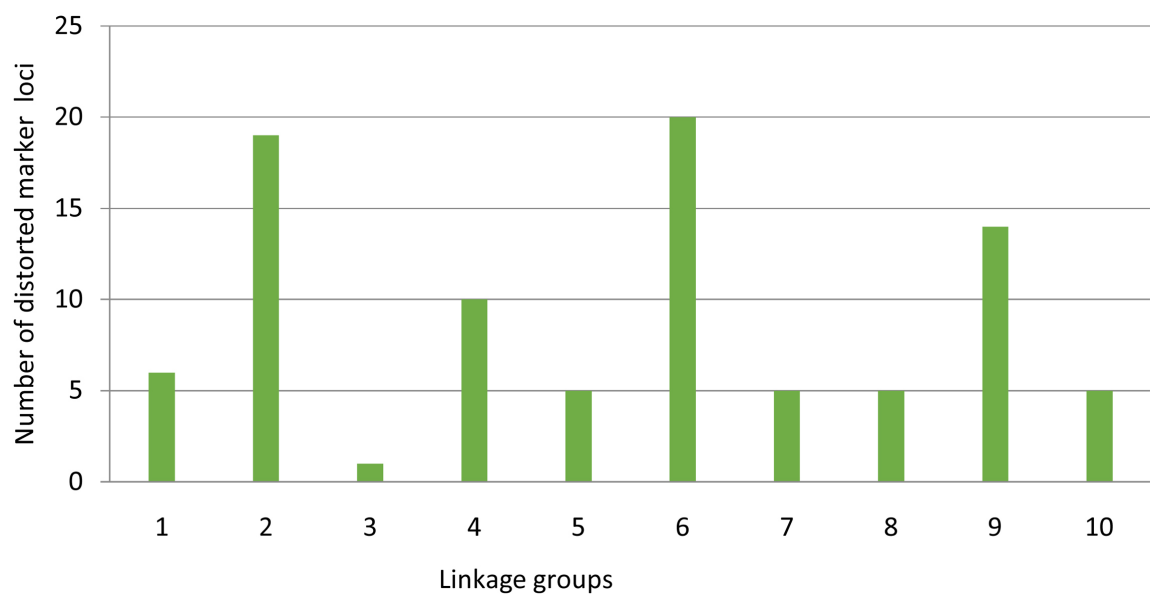

Figure 4. Marker loci showing distorted segregation resulting from $\mathrm{x}^{2}$ test.

Table 2. Heritability for GYLD, PHT and EHT of maize F3 population in low P soils.

\begin{tabular}{cccccccccc}
\hline & \multicolumn{3}{c}{ Parents } & \multicolumn{5}{c}{ F3 segregating population } \\
\hline Trait & KML 036 S 396-16-1 & Mean & Median & Lower & Upper & Mean & Standard Heritability \\
\hline & & & & & Quartile & Quartile & deviation \\
\hline $\begin{array}{r}\text { GYLD } \\
\text { (t/ha) }\end{array}$ & 2.5 & 0.4 & 1.5 & 2.4 & 1.6 & 3.4 & 2.7 & 1.5 & 0.32 \\
PHT (cm) & 150 & 125 & 137.5 & 170 & 153.3 & 186.7 & 169.2 & 24.3 & 0.55 \\
EHT (cm) & 60 & 40 & 50 & 53.3 & 43.3 & 63.3 & 53.9 & 15.9 & 0.38 \\
\hline
\end{tabular}

GYLD-grain yield, PHT-plant height, EHT-ear height.

attributed to the larger environmental component to the variance associated with stressed environments. The findings of this study further compares well with those of [35] who reported heritability ranging from 0.23 to 0.58 for grain yield and anther silk interval for 18 maize bi-parental populations.

There was significant and high to moderate positive genetic correlation between GYLD, PHT and EHT (Table 3). The high positive and significant genetic correlation between PHT and EHT $\left(\mathrm{r}_{\mathrm{g}}=0.78^{* *}\right)$ under low P conditions may suggest that the duo traits may be controlled by similar QTLs or those located in the same chromosomal position. Studies by [35] reported low to medium significant genetic correlations between GYLD and anther silk interval (ASI) although their correlations were negative because of the inverse relationship expected between grain yields and flowering characteristics. These findings also agree well with those of [50] [53] [54] [55] who all reported significant genetic correlation between grain yield in maize and other agronomic attributes such as plant height, ear height and days to $50 \%$ flowering.

\subsection{QTL Detection in F2:3 Populations}

A total of 6 QTL were detected: 2, QTLs each for GYLD designated (CIP49 and PZAO2454-2), PHT (C8P114 and C8P247) and EHT (C3P122 and PHM 4586-12). The QTLs were non-uniformly distributed across the chromosomes 
Table 3. Genetic correlations between grain yield pant height and Ear heights of F2:3 segregating populations.

\begin{tabular}{cccc}
\hline PHT & - & & \\
EHT & $0.788^{* *}$ & - & \\
GYLD & $0.56^{*}$ & $0.45^{*}$ & - \\
& PHT & EHT & GYLD \\
\hline
\end{tabular}

(Table 4, Figures 5(a)-(c)). For GYLD, they were located on chromosome 1 and 4 while for both PHT and EHT, the 3 QTLs were located on chromosome 8 while one for EHT on chromosome 3. Both additive and dominance gene actions contributed differentially to the observed phenotypic variance for tolerance to low $\mathrm{P}$ soils with dominance contribution being more important compared to the additive ones for majority of the QTLs. For grain yield the two QTLs increased grain yield by $173 \mathrm{~kg} / \mathrm{ha}$ (additive effects) with KML 036 being the contributor of the favourable alleles resulting in the yield increase (Table 4). The 2 QTLs for plant height increased plant height by $18.14 \mathrm{~cm}$ while the EHT QTLs gave an increase of $3.67 \mathrm{~cm}$. For grain yield, both the high value and the dominant alleles for the 2 QTLs always came from the first parent (KML 036), however for PHT and EHT, the dominant allele was sometimes coming from the second parent (S396-16-1). The \% phenotypic variance explained by these QTLs under low $\mathrm{P}$ environments had a wide range $(0.242 \%-53.34 \%)$ and were much lower for grain yield compared to plant growth. These results compare well with those of [35] who reported between $1.3 \%$ to $8.4 \%$ explained variance in maize under drought stress conditions. It also agrees with those of [27] who reported $24 \%$ - 35\% range for P utilization efficiency in maize and those of [32] who reported a range of $38 \%-64 \%$ of explained variance for phosphorus efficiency QTLs. The latter authors also identified QTLs for P acquisition efficiency and utilization efficiency on chromosomes 1, 3, 4, 5, 7 and 8 which coincides with the ones in the current study that were identified on chromosome 1, 3, 4 and 8. The information presented here is useful and will guide further breeding for tolerance to low $\mathrm{P}$ soils.

\section{Conclusions and Recommendations}

A total of 6 QTLs located on chromosomes 1, 3, 4 and 8 were detected: 2 QTLs each for GYLD, PHT and EHT. The QTLs were non-uniformly distributed across the chromosomes and coincided with those identified in previous studies. Both additive and dominance gene actions contributed differentially to the observed phenotypic variance for tolerance to low $\mathrm{P}$ soils with dominance contribution being more important compared to the additive one for majority of the QTLs. The newly QTLs identified under low P conditions will be useful for improving maize productivity in low $\mathrm{P}$ soils of western Kenya. It's recommended that further studies be done to validate the identified QTLs in other populations and also to further characterize the QTL loci to identify the specific genes 
Table 4. QTLs associated with low $\mathrm{P}$ tolerance traits their position and effects in maize F2:3 populations.

\begin{tabular}{|c|c|c|c|c|c|c|c|c|c|}
\hline \multicolumn{10}{|c|}{ Grain yield (t/ha) } \\
\hline Locus & Lucus & Linkage & QTL & \% Expl. & Additive & High value & Dominance & Diminant & \multirow{2}{*}{$\sim-\log 10(\mathrm{P})$} \\
\hline no. & name & group & position & Variance & effects & Allele & effect & allele & \\
\hline 228 & PZA02454_2 & 4 & 76.8 & 0.242 & 0.053 & KML_036 & 0.339 & KML_036 & 3.559 \\
\hline \multicolumn{10}{|c|}{ Plant height $(\mathrm{cm})$} \\
\hline 494 & C8P247 & 8 & 246.54 & 2.856 & 3.409 & KML_036 & 10.16 & KML_036 & 3.972 \\
\hline \multicolumn{10}{|c|}{ Ear Height $(\mathrm{cm})$} \\
\hline 191 & C3P122 & 3 & 121.81 & 7.075 & 3.016 & KML_036 & * & * & 3.134 \\
\hline 497 & PHM4586_12 & 8 & 259.5 & 0.336 & 0.657 & KML_036 & 3.518 & S 396-16-1 & 3.238 \\
\hline
\end{tabular}
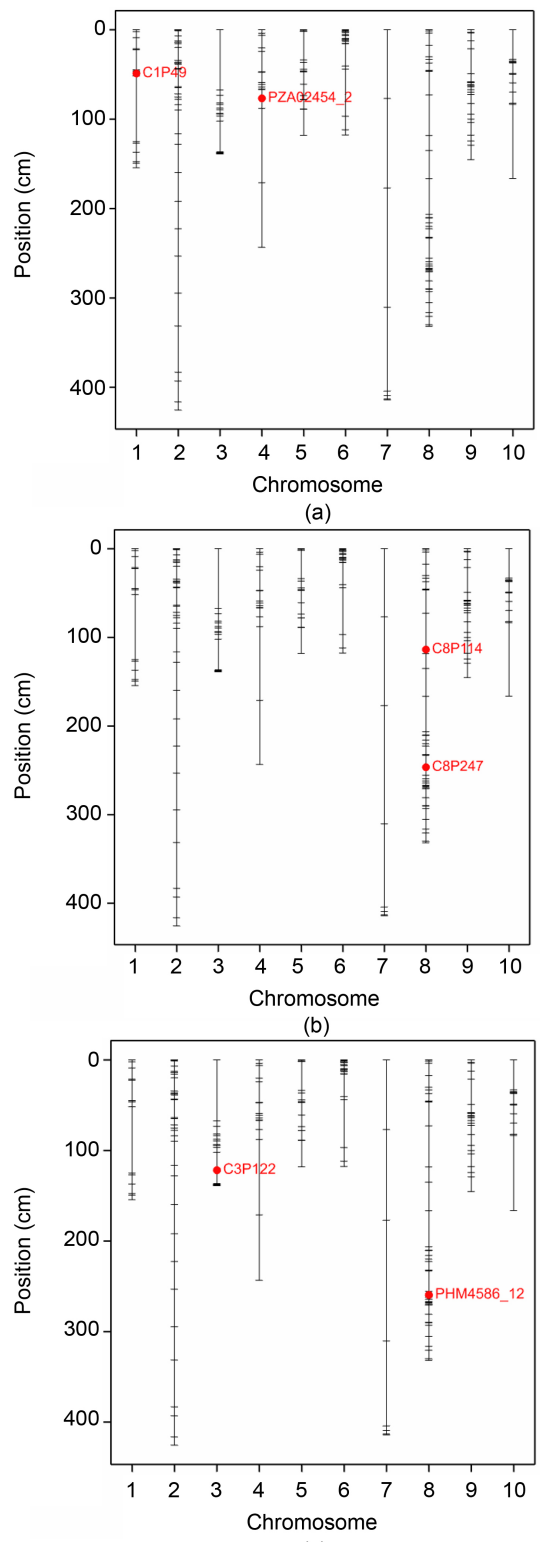

(c)

Figure 5. (a) The genetic map of the identified grain yield QTLs: the red bulletin shows the locus name and the QTL position on the genetic map. (b) The genetic map of the identified plant height QTLs. (c) The genetic map for EarHeight QTLs. 
responsible for tolerance to low $\mathrm{P}$.

\section{Acknowledgements}

The authors are grateful to Generation challenge programme (GCP) for the funding. We also thank LGC Genomics for SNP Genotyping.

\section{Conflicts of Interest}

The authors declare no conflicts of interest regarding the publication of this paper.

\section{References}

[1] White, P.J. and Hammond, J.P. (2008) Phosphorus Nutrition of Terrestrial Plants. In: White, P.J. and Hammond, J.P., Eds., The Ecophysiology of Plant Phosphorus Interactions, Vol. 7, Springer, Dordrecht, 51-81. https://doi.org/10.1007/978-1-4020-8435-5_4

[2] Ozturk, L., Eker, S., Torum, B. and Cakmak, I. (2005) Variation in Phosphorus Efficiency among 73 Bread and Durum Wheat Genotypes Grown in a Phosphorus-Deficient Calcareous Soil. Plant and Soil, 269, 69-80. https://doi.org/10.1007/s11104-004-0469-z

[3] Lynch, J.P. (2011) Root Phenes for Enhanced Soil Exploration and Phosphorus Acquisition: Tools for Future Crops. Plant Physiology, 156, 1041-1049.

https://doi.org/10.1104/pp.111.175414

[4] Tilman, D., Cassman, K.G., Matson, P.A., Naylor, R. and Polasky, S. (2002) Agricultural Sustainability and Intensive Production Practices. Nature, 418, 671-677. https://doi.org/10.1038/nature01014

[5] Cordell, D. and White, S. (2013) Sustainable Measures: Strategies and Technologies for Achieving Phosphorus Security. Agronomy, 3, 86-116.

https://www.mdpi.com/2073-4395/3/1/86

https://doi.org/10.3390/agronomy3010086

[6] Obersteiner, M., Penielas, J, Clais, P., Van der Velde, M. and Janssen, I.A. (2013) The Phosphorus Trielema. Nature Geoscience, 6, 897-898.

https://doi.org/10.1038/ngeo1990

[7] Ouma, E.O. (2016) Inheritance of Maize Phosphorus Efficiency in Acid Soils of Western Kenya. International Journal of Information Research and Review, 3, 2091-2097. http://repository.rongovarsity.ac.ke/handle/123456789/2257

[8] Parentoni, S.N., Souza, J.R., Alves, V.M.C., Gama, E.E.G., Coelho, A.M., Oliveira, A.C., Guimaraes, P.E.O., Guimaraes, C.T., Vasconcelos, M.J.V., Pacheco, C.A.P., Magalhães, J.V., Meirelles, W.F., Guimarães, L.J.M., Silva, A.R., Mendes, F.F. and Schaffert, R.E. (2010) Inheritance and Breeding Strategies for Phosphorus Efficiency in Tropical Maize (Zea mays L.). Maydica, 55, 1-15. https://www.researchgate.net/publication/285752925

[9] Yu, X., Zhang, M., Yu, Z., Yang, D., Li, J., Wu, G. and Li, J. (2020) An SNP-Based High-Density Genetic Linkage Map for Tetraploid Potato Using Specific Length Amplified Fragment Sequencing (SLAF-Seq) Technology. Agronomy, 10, Article No. 114. https://doi.org/10.3390/agronomy10010114

[10] Ouma, E., Ligeyo, D., Matonyei, T., Were, B., Agalo, J., Emily, T., Onkware, A., Gudu, S., Kisinyo, P., Okalebo, J. and Othieno, C. (2012) Development of Maize Single cross Hybrids for Tolerance to Low Phosphorus. African Journal of Plant 
Science, 6, 394-402. http://www.academicjournals.org/AJPS

[11] Maron, L.G., Guimarães, C.T., Kirst, M., Alberte, P.S., Birchlere, J.A., Bradbury, P.J., Buckler, E.S., Coluccio, A.E., Danilova, T.V., Kudrna, D., Magalhaes, J.V., Piñeros, M.A., Schatzh, M.C., Wing, R.A. and Kochian, L.V. (2014) Aluminum Tolerance in Maize Is Associated with Higher MATE1 Gene Copy Number. Proceedings of the National Academy of Sciences of the United States of America, 110, 5241-5246.

https://www.pnas.org/cgi/doi/10.1073/pnas.1220766110

https://doi.org/10.1073/pnas.1220766110

[12] Guimraes, C.T., Christiano, C.S., Maria, M.P., Maron L.G., Jurandir V.M. Renato, C.C.V., Lauro, J.M.G., Ubiraci, G.P.L., Carlos, F.S.T., Roberto, W.N., Silvia, N.J.B., Leon, V.K., Vera, M.C.A. and Sydney, P.N. (2014) Genetic Dissection of Al Tolerance QTLs in the Maize Genome by High Density SNP Scan. BMC Genomics, 15, Article No. 153. https://doi.org/10.1186/1471-2164-15-153

[13] Yuan, Y., Gao, M., Zhang, M., Zheng, H., Zhou, X., Guo, Y., Zhao, Y., Kong, F. and Li, S. (2017) Mapping for Phosphorus Efficiency and Morphological Traits at Seedling and Maturity Stages in Wheat. Frontiers in Plant Science, 8, Article No. 614. https://doi.org/10.3389/fpls.2017.00614

[14] Su, C., Wang, W., Gong, S., Zuo, J., Li, S. and Xu, S. (2017) High Density Linkage Map Construction and Mapping of Yield Trait QTLs in Maize (Zea mays) Using the Genotyping-by-Sequencing (GBS) Technology. Frontiers in Plant Science, 8, Article No. 706. https://doi.org/10.3389/fpls.2017.00706

[15] Jarne, P. and Lagoda, P. (1996) Microsatellites, from Molecules to Populations and Back. Trends in Ecology and Evolution, 11, 424-429.

https://doi.org/10.1016/0169-5347(96)10049-5

[16] Hamblin, M.T, Warburton, M.L. and Buckler E.S. (2007) Empirical Comparison of Simple Sequence Repeats and Single Nucleotide Polymorphisms in Assessment of Maize Diversity and Relatedness. PLoS ONE, 2, e1367.

https://doi.org/10.1371/journal.pone.0001367

[17] Jones, E.S., Sullivan, H., Bhattramakki, D. and Smith, J.S.C. (2007) A Comparison of Simple Sequence Repeat and Single Nucleotide Polymorphism Marker Technologies for the Genotypic Analysis of Maize (Zea mays L.). Theoretical and Applied Genetics, 115, 361-371. https://doi.org/10.1007/s00122-007-0570-9

[18] Ganal, M.W., Durstewitz, G., Polley, A., Bérard, A., Buckler, E.S., et al. (2011) A Large Maize (Zea mays L.) SNP Genotyping Array: Development and Germplasm Genotyping, and Genetic Mapping to Compare with the B73 Reference Genome. PLOS ONE, 6, e28334. https://pubmed.ncbi.nlm.nih.gov/22174790 https://doi.org/10.1371/journal.pone.0028334

[19] Rafalski, A. (2002) Applications of Single Nucleotide Polymorphisms in Crop Genetics. Current Opinion in Plant Biology, 5, 94-100. https://doi.org/10.1016/S1369-5266(02)00240-6

[20] Zhu, Y.L., Song, Q.J., Hyten, D.L., Van Tassell, C.P., Matukumalli, L.K. and Grimm, D.R. (2003) Single-Nucleotide Polymorphisms in Soybean. Genetics, 163, 1123-1134. https://doi.org/10.1093/genetics/163.3.1123

[21] Dreisigacker, S., Sehgal, D., Reyes Jaimez, A.E., Luna Garrido, B., Muñoz Zavala, S., Núñez Ríos, C., Mollins, J. and Mall, S. (Eds.) (2016) CIMMYT Wheat Molecular Genetics: Laboratory Protocols and Applications to Wheat Breeding. International Maize and Wheat Improvement Center (CIMMYT), Mexico, D.F. https://www.researchgate.net

[22] Wissuwa, M. and Ae, N. (2001) Further Characterization of Two QTLs that Increase 
Phosphorus Uptake of Rice (Oryza sativa L.) under Phosphorus Deficiency. Plant Soil, 237, 275-286. https://link.springer.com/article/10.1023/A:1013385620875 https://doi.org/10.1023/A:1013385620875

[23] Chin, H.J., Lu, X., Haefele, S.M., Gamuyao, R., Ismail, A.M., Wissuwa, M. and Heuer, S. (2010) Development and Application of Gene-Based Markers for the Major rice QTL Phosphate uptake 1 (Pup1). Theoretical and Applied Genetics, 120, 1073-1086. https://doi.org/10.1007/s00122-009-1235-7

[24] Gamuyao, R., Chin, J.H., Pariasca-Tanaka, J., Pesaresi, P., Catausan, S., Dalid, C., Slamet-Loedin, I., Tecson-Mendoza, E.M., Wissuwa, M. and Heuer, S. (2012) The Protein Kinase Pstol1 from Traditional Rice Confers Tolerance of Phosphorus Deficiency. Nature, 488, 535-539. https://www.nature.com/articles/nature11346 https://doi.org/10.1038/nature11346

[25] Hufnagel, B., Sylvia, M.S., Lidianne, A., Claudia, T.G., Willmar, L., Gabriel, C.A., Barbara, N., Brandon, G.L., Jon, E.S., Maria, M.P., Beatriz, A.B., Eva, W., Frederick, W.R., Joao, H.V., Randy, T.C., Alexandre, F., Rodrigo, G., Antonio, A.F., Robert, E.S., Leon, V.K. and Jurandir, V.M. (2014) Duplicate and Conquer: Multiple Homologs of Phosphorus-Starvation Tolerancel Enhance Phosphorus Acquisition and Sorghum Performance on Low-Phosphorus. Soils Plant Physiology, 166, 659-677. https://doi.org/10.1104/pp.114.243949

[26] Bernardino, K.C., Pastina, M.M., Menezes, C.B., et al. (2019) The Genetic Architecture of Phosphorus Efficiency in Sorghum Involves Pleiotropic QTL for Root Morphology and Grain Yield under Low Phosphorus Availability in the Soil. BMC Plant Biology, 19, Article No. 87. https://doi.org/10.1186/s12870-019-1689-y

[27] Chen, J., Xu, L., Cai, Y. and Xu, J. (2009) Identification of QTLs for Phosphorus Utilization Efficiency in Maize (Zea mays L.) across P Levels. Euphytica, 167, 245-252. https://doi.org/10.1007/s10681-009-9883-x

[28] Chen, J., Cai, Y., Xu, L., Wang, J., Zhang, W., Wang, G., Xu, D., Chen, T., Lu, X., Sun, H., Huang, A., Liang, Y., Dai, G., Qin, H., Huang, Z., Zhu, Z., Yang, Z., Xu, J. and Kuang, S. (2011) Identification of QTLs for Biomass Production in Maize (Zea mays L.) under Different Phosphorus Levels at Two Sites. Frontiers of Agriculture in China, 5, 152-161. https://doi.org/10.1007/s11703-011-1077-3

[29] Maia, C., do Vale, J.C., Fritsche-Neto, R., Cavatte, P.C. and Miranda, G.V. (2011) Difference between Breeding for Nutrient Use Efficiency and Nutrient Stress Tolerance. Crop Breeding and Applied Biotechnology, 11, 270-275. https://doi.org/10.1590/S1984-70332011000300010

[30] de Sousa, S.M., Randy, T., Clark, R.T., Mendes, F.F., Oliveira, A.C., Vasconcelos, M.J.V., Parentoni, S.N., Kochian, L.V., Guimarães, C.T. and Magalhães, J.V. (2012) A Role for Root Morphology and Related Candidate Genes in P Acquisition Efficiency in Maize. Functional Plant Biology, 39, 925-935.

https://doi.org/10.1071/FP12022

[31] Azevedo, G.C., Cheavegatti-Gianotto, A., Negri, B.F., Hufnagel, B., da Costa e Silva, L., Magalhaes, J.V., et al. (2015) Multiple Interval QTL Mapping and Searching for PSTOL1 Homologs Associated with Root Morphology, Biomass Accumulation and phosphorus Content in Maize Seedlings under Low-P. BMC Plant Biology, 15, Article No. 172. https://doi.org/10.1186/s12870-015-0561-y

[32] Mendes, F.F., Guimarães, L.J.M., Souza, J.C., Guimarães, P.E.O., Magalhaes, J.V., Garcia, A.A.F., et al. (2015) Genetic Architecture of Phosphorus Use Efficiency in Tropical Maize Cultivated in a Low-P Soil. Crop Science, 54, 1530-1538. https://doi.org/10.2135/cropsci2013.11.0755

[33] Hoisington, D., Khairallah, M. and Gonzalez-de-Lion, D. (1994) Laboratory Proto- 
cols: CIMMYT Applied Molecular Genetics Laboratory. 2nd Edition, International Maize and Wheat Improvement Center (CIMMYT), Mexico, DF.

[34] Gaur, R., Azam, S., Jeena, G., Choudhary, S., Jain, M., Yadav, G., Tyagi, A.K., Chattopadhyay, D. and Bhatia, S. (2012) High-Throughput SNP Discovery and Genotyping for Constructing a Saturated Linkage Map of Chickpea (Cicer arietinum L.). DNA Research, 19, 357-373. https://doi.org/10.1093/dnares/dss018

[35] Semagn, K., Cosmos, M., Bindiganavile, S., Dan, M., Yoseph, B., Stephen, M., Prasanna, B. and Warburton, M. (2012) Molecular Characterization of Diverse CIMMYT Maize Inbred Lines from Eastern and Southern Africa Using Single Nucleotide Polymorphic Markers. BMC Genomics, 13, Article No. 113. https://doi.org/10.1186/1471-2164-13-113

[36] Deng, Y., Chen, K., Teng, W., Zhan, A., Tong, Y., Feng, G., et al. (2014) Is the Inherent Potential of Maize Roots Efficient for Soil Phosphorus Acquisition? PLoS ONE, 9, e90287. https://doi.org/10.1371/journal.pone.0090287

[37] Li, M., Guo, X., Zhang, M., Wang, X., Zhang, G., Tian, Y. and Wang, Z. (2010) Mapping QTLs for Grain Yield and Yield Components under High and Low Phosphorus Treatments in Maize (Zea mays L.). Plant Science, 178, 454-462.

https://doi.org/10.1016/j.plantsci.2010.02.019

[38] Kosambi, D.D. (1944) The Estimation of Map Distances from Recombination Values. Annals of Eugenics, 12, 172-175.

https://doi.org/10.1111/j.1469-1809.1943.tb02321.x

[39] VSN International (2015) GenStat for Windows. 18th Edition. VSN International, Hemel Hempstead. Genstat.co.uk https://find-and-update.company-information.service.gov.uk/company/04027977

[40] Kearsey, M.J. and Pooni, H.S. (1998) The Genetically Analysis of Quantitative Traits. Chapman and Hall, London. http://dx.doi.org/10.1007/978-1-4899-4441-2

[41] Ribaut, J.M., Hoisington, D.A., Deutsch, J.A., Jiang, C. and Gonzalez-de-Leon, D. (1996) Identification of Quantitative Trait Loci under Drought Conditions in Tropical Maize. I. Flowering Parameters and the Anthesis-Silking Interval. Theoretical and Applied Genetics, 92, 905-914. https://doi.org/10.1007/BF00221905

[42] Jansen, R.C. and Stam, P. (1994) High Resolution of Quantitative Traits into Multiple Loci via Interval Mapping. Genetics, 136, 1447-1455. https://doi.org/10.1093/genetics/136.4.1447

[43] Zeng, Z.B. (1994) Precision Mapping of Quantitative Trait Loci. Genetics, 136, 1457-1468. https://doi.org/10.1093/genetics/136.4.1457

[44] Lander, E.S. and Botstein, D. (1989) Mapping Mendelian Factors Underlying Quantitative Traits Using RFLP Linkage Maps. Genetics, 121, 185-199 https://www.genetics.org/content/genetics/121/1/185.full.pdf https://doi.org/10.1093/genetics/121.1.185

[45] Utz, H.F. and Melchinger, A.E. (1996) PLABQTL: A Program for Compolocation Interval Mapping of QTL. Journal of Quantitative Trait Loci, 2, 1-9. http://probe.nalusda.gov:8000/otherdocs/jqtl

[46] Liu, B. (1998) Statistical Genomics: Linkage, Mapping and QTL Analysis. CRC Press, Boca Raton. https://www.amazon.com/Statistical-Genomics

[47] Milne, I., Shaw, P., Stephen, G., Bayer, M., Cardle, L., Thomas, W.T.B., Flavell, A.J. and Marshall, D. (2010) Flapjack-Graphical Genotype Visualization. Bioinformatics, 26, 3133-3134. https://doi.org/10.1093/bioinformatics/btq580

[48] Wang, A.-Y., Li, Y. and Zhang, C.-Q. (2012) QTL Mapping for Stay-Green in Maize 
(Zea mays). Canadian Journal of Plant Science, 92, 249-256. https://doi.org/10.4141/cjps2011-108

[49] Choudhary, S., Gaur, R., Gupta, S. and Bhatia, S. (2012) EST-Derived Genic Molecular Markers: Development and Utilization for Generating an Advanced Transcript Map of Chickpea. Theoretical and Applied Genetics, 124, 1449-1462. https://doi.org/10.1007/s00122-012-1800-3

[50] Ouma, E.O. (2021) Evaluating Heritability and Relationships among Phosphorus Efficiency Traits in Maize under Low P Soils of Western Kenya. Current Journal of Applied Science and Technology, 40, 83-96. https://doi.org/10.9734/cjast/2021/v40i1131373

[51] Weber, V.S., Melchinger, A.E., Magorokosho, C., Makumbi, D., BÃnziger, M. and Atlin, G.N. (2012) Efficiency of Managed-Stress Screening of Elite Maize Hybrids under Drought and Low Nitrogen for Yield under Rain Fed Conditions in Southern Africa. Crop Science, 52, 1011-1020. https://doi.org/10.2135/cropsci2011.09.0486

[52] Edmeades, G.O., Bolaños, J., Chapman, S.C., Lafitte, H.R. and Bänziger, M. (1999) Selection Improves Drought Tolerance in Tropical Maize Populations. Crop Science, 39, 1306-1315. https://doi.org/10.2135/cropsci1999.3951306x

[53] Mohan, Y.C., Singh, K. and Rao, N.V. (2002) Path Coefficient Analysis for Oil and Grain Yield in Maize Genotypes. National Journal of Plant Improvement, 4, 75-76. https://www.researchgate.net/publication/326246902

[54] Rafiq, C.M., Rafique, M. and Hussain, A. (2010) Studies on Heritability, Path Analysis in Maize (Zea mays L.) Journal of Agricultural Research, 48, 1-35. https://apply.jar.punjab.gov.pk/upload/1374660174

[55] Aminu, D. and Izge, A.U. (2012) Heritability and Correlation Estimates in Maize under Drought Conditions in Northern Guinea and Sudan Savannas of Nigeria. World Journal of Agricultural Sciences, 8, 598-602. https://link.citeseerx.ist.psu.edu/viewdoc/download?doi=10.1.1 